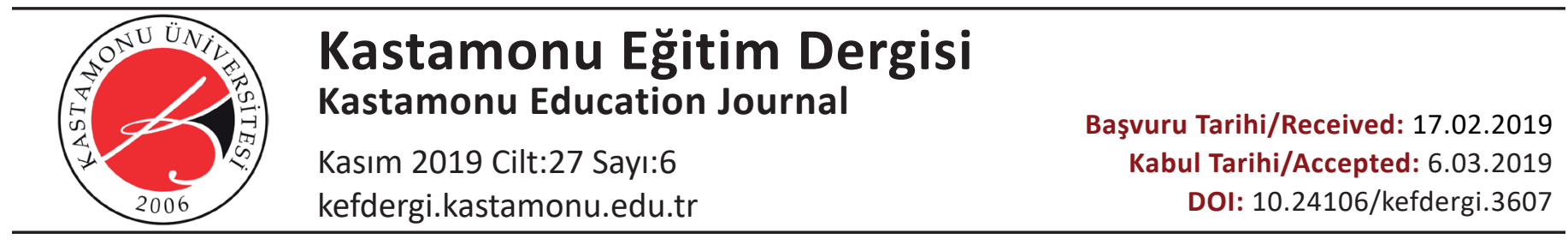

\title{
Muhasebe Eğitimi Alan Lisans Öğrencilerinin TFRS (Türkiye Finansal Raporlama Standartları)/ TMS (Türkiye Muhasebe Standartları) Farkındalıklarının Belirlenmesine Yönelik Bir Araştırma
}

\section{A Study on Determination of TFRS (Turkish Financial Reporting Standards )/ TAS (Turkish Accounting Standards) Awareness of Undergraduate Students Receiving Accounting Education}

\author{
Öz \\ Kezban ŞiMŞEK ${ }^{1}$, Onur ŞiMŞEK²
}

Bu araşttrma, muhasebe eğitimi alan lisans öğrencilerinin Türkiye Finansal Raporlama Standartları (TFRS) ve Türkiye Muhasebe Standartları (TMS)' na ilişkin farkındalıklarını belirleme amacı taşımaktadır. Bu amacı gerçekleştirmek için ihtiyaç duyulan verilerin toplanmasında anket yöntemi kullanılmıştır. Anket Kastamonu Üniversitesi iktisadi ve İdari Bilimler Fakültesi İşletme ile Bankacılık ve Finans Bölümlerinde öğrenim gören 237 lisans öğrencisine uygulanmıştr. Araşttrma sonucunda İşletme bölümü öğrencileri ile Bankacılık ve Finans bölümü öğrencileri arasında TFRS/TMS farkındalık düzeyleri bakımından anlamlı bir farklılık olduğu tespit edilmiştir. Araştırma bulguları, TFRS / TMS bilgisine sahip olan ve TFRS / TMS bilgisine sahip olmayan öğrenciler arasında da TFRS / TMS farkındalık düzeyleri açısından anlamlı bir fark olduğunu ortaya koymuştur.

Anahtar Kelimeler: muhasebe eğitimi, tfrs, tms, farkındalık düzeyi

\section{Abstarct}

This research aims to determine the Turkish Financial Reporting Standards (TFRS) and Turkish Accounting Standards (TAS) awareness of undergraduate students having education in accounting. The questionnaire method was used to collect the data needed to accomplish this aim. The questionnaire was applied to 237 undergraduate students in The Departments of Business Administration and Banking and Finance in Faculty of Economics and Administrative Sciences at Kastamonu University. As a result of the study, it was determined that there was a significant difference in terms of TFRS / TAS awareness levels between the students in The Departments of Business Administration and Banking and Finance. The findings of the study revealed that there was a significant difference in terms of TFRS / TAS awareness levels between students who have TFRS / TAS knowledge and who do not have TFRS / TAS knowledge.

Key Words: accounting education, tfrs, tas, awareness level

1. Kastamonu Üniversitesi, Cide Rıfat Ilgaz Meslek Yüksekokulu, Kastamonu, Türkiye; https://orcid.org/0000-0002-2365-6163,

2. Kastamonu Üniversitesi, Cide Rıfat Ilgaz Meslek Yüksekokulu, Muhasebe ve Vergi Bölümü, Kastamonu, Türkiye; https://orcid.org/ 0000-0003-2411-8655

Atıf / Citation: Şimşek, K. ve Şimşek, O. (2019). Muhasebe eğitimi alan lisans öğrencilerinin TFRS (Türkiye Finansal Raporlama Standartları)/ TMS (Türkiye Muhasebe Standartları) farkındalıklarının belirlenmesine yönelik bir araştırma. Kastamonu Education Journal, 27(6), 2693-2700. doi:10.24106/ kefdergi.3607 


\section{Extended Abstract}

Purpose of study: The obligation to apply TFRS (Turkish Financial Reporting Standards)/ TAS (Turkish Accounting Standards) to the Turkish Commercial Code has created a number of changes in the existing accounting practices in order to produce accounting information as required by the standards (Gökçen et. al., 2015). It has become a necessity to give these up-to-date practices in accounting field to accounting profession candidates in accounting education and raise awareness of TFRS / TAS (Patro and Gupta; 2012). IAESB (International Accounting Education Standards Board) President Chris Austin said that "Accounting training is the main carrier that increases the quality of reporting and audited financial statements". As stated by the expression the most important factor in ensuring the quality of the service provided by the accounting profession is the existence of an accounting education which can meet the requirements of the profession by adapting to the development and change experienced (TÜRMOB, 2016). In this sense, it is important that the students having education in accounting should have awareness about TFRS / TAS applications as the most important development guiding the accounting profession. Within this conceptual scope, in this study, an empirical study was conducted to determine the TFRS / TAS awareness of undergraduate students having education in accounting. The problems of the study are as follows;

- Do the students having education in accounting have information about TFRS / TAS?

- Do the students having education in accounting have enough information reated to TFRS / TAS content?

- From which sources do undergraduate students having education in accounting obtain information on TFRS / TAS content?

- Do the awareness levels of the undergraduate students having education in accounting differ according to the department they are studying?

- Do the awareness levels of the undergraduate students having education in accounting differ according to their TFRS / TAS knowledge?

Method: This research is a "descriptive" study aiming to reveal the awareness level related to TFRS / TAS of the undergraduate students having education in accounting. A total of 237 students from The Departments of Business Administration and Banking and Finance in Faculty of Economics and Administrative Sciences at Kastamonu University attended the study. In this study, questionnaire was used as data collection tool. The questionnaire was developed in utilizing previous studies (Dalğar, Çelik and Mortaş, 2011; Patro and Gupta, 2012; Ülkü and Gökgöz, 2013; Erol Fidan and Uysal, 2017) accordance with the research purpose. The data collected as a result of the application were analyzed by SPSS program and the findings obtained from the analyzes were interpreted in accordance with the purpose of the study. The Cronbach's alpha $(\alpha)$ of the pre-applied scale was found to be 0.87 .

Finding and Discussion: It was found that $65.8 \%$ of undergraduate students have knowledge about TFRS / TAS, $5.9 \%$ of those who have knowledge about TFRS / TAS have sufficient knowledge of TFRS / TAS content. $6.3 \%$ of those who have knowledge about TFRS / TAS doesn't have sufficient information. $81.4 \%$ of those who have knowledge of TFRS / TAS have been found to have in part sufficient knowledge of TFRS / TAS content.

In the study examining the TFRS / TAS awareness of undergraduate students having education in accounting, it has been found that TFRS / TAS awareness differs significantly according to the department studied. The level of awareness of students studying in The Departments of Banking and Finance departments is higher than those in Business Administration. This result may be related to the finding of courses related to TFRS / TAS in the curriculum of the Department of Banking and Finance. Kurnaz (2012) showed a similar result as our study.

Another finding of the study is that most of the undergraduate students $(40.5 \%)$ having education in accounting acquired TFRS / TAS knowledge from a separate course in the curriculum. This finding reveals the necessity to include courses that will include TFRS / TAS training in the undergraduate programs of universities that are preparing candidates for professional accountancy.

There was a significant difference in terms of TFRS / TAS awareness levels between students who have TFRS / TAS knowledge and who do not have TFRS / TAS knowledge. Accordingly, it is found out that students who have TFRS / TAS knowledge have higher levels of awareness than students who do not have TFRS / TAS knowledge. This result reveals the importance of knowledge in terms of TFRS / TAS awareness.

As in every field, it is very important to have up-to-date knowledge in terms of accounting education. TFRS / TAS is the most recent and important development in accounting. Therefore, the training of professional accountants with TFRS / TAS knowledge is a necessity to achieve quality in accounting education. 


\section{Giriş}

Bilgi teknolojilerinin yaşadığı hızlı gelişim, sınırları ortadan kaldırırken küreselleşme olgusunu hızlandırmıştr. Küreselleşme beraberinde sınır ötesi sermaye hareketliliğinin de önünü açmış, sınır ötesi şirket birleşmelerinin ve hisse alım satımının sayısı artmış ve çok uluslu işletmeler ortaya çıkmaya başlamıştı (Karabayır ve Ertugay, 2014). Uluslararası bu sermaye hareketliliği ile sistematik riskler şirketlerin finansal yapılarını karmaşık hale getirmiştir (Ulusoy, 2008). Karmaşıklığın önüne geçebilmek için dünyada ortak bir takım metotların özellikle de kayıt ve raporlama mekanizmalarının yeniden gözden geçirilmesi önem kazanmıştır. Tüm bu sebepler, muhasebe bilgi sistemi tarafindan üretilen bilgilerin gerçeğe uygun, güvenilir, şeffaf ve karşılaştrılabilir $(A y c ı, 2012)$ bir şekilde dünya çapında paylaşımını mümkün kılacak ortak bir dil ihtiyacını doğurmuştur (Ülkü ve Gökgöz, 2013). Söz konusu bu ortak dil ihtiyacı yayınlanan Uluslararası Finansal Raporlama Standartları (UFRS) ve Uluslararası Muhasebe Standartları (UMS) ile karşılanmaya çalışılmıştır (Gökçen ve diğ., 2015).

Finansal raporların dünya çapında anlaşılmasını sağlama, şirketlerin farklı raporlama uygulamalarını uyumlaştırma ve karşılaştrılabilir güvenilir bilgi sunma amacı ile başlatılan standart oluşturma süreci (Dalğar, Çelik ve Mortaş, 2015) 1973 yılında Uluslararası Muhasebe Standartları Komitesi'nin (International Accounting Standards Committee - IASC) kurulmasıyla hız kazanmaya başlamıştır (Zeff, 2016).

Merkezi Londra' da bulunan IASC tarafindan ilk standart 1975 yılında yayımlanmış, 1982 yılında IASC ile Uluslararası Muhasebeciler Federasyonu (International Federation of Accountants - IFAC), finansal verilerin ölçümünde ve sunumunda dünya çapında standart getirmek, uluslararası finans dili oluşturmak ve muhasebe uygulamalarında birlik sağlamak amacı ile birlikte hareket etme kararı vermişlerdir (Durmuş ve Aytulun, 2016).

Bir grup profesyonel muhasebe uygulayıCıSı tarafindan kurulan IASC, yirmi yılı aşkın bir süre aktif olarak hizmet etmiştir. IASC tarafindan 2001 yılına kadar bir kısmı iptal ve revizyon edilmiş olmakla birlikte toplam 41 adet standart yayımlanmıştır (Durmuş ve Aytulun, 2016). Nisan 2001' de Uluslararası Muhasebe Standartları Kurulu (International Accounting Standards Board - IASB), Uluslararası Muhasebe Standartları Komitesinin (IASC)' nin görevini devralarak halihazırda mevcut olan Uluslararası Muhasebe Standartlarını güncellemiş ve Uluslararası Finansal Raporlama Standartları (UFRS) olarak adlandırmıştır (Madawaki, 2012). Tüm dünyada ortak muhasebe ve finansal raporlama seti olarak kabul gören UFRS' lerin belirlenmesi ve yayımlanması görevi 2001 yılından bu yana IASB' ye aittir (Durmuş ve Aytulun, 2016).

UFRS/UMS' lerin uluslararası anlamda kabul görmesinde Avrupa Birliği' nin bankalar ve sigorta şirketleri de dahil olmak üzere borsaya kote şirketlere, 2005 yılından itibaren konsolide mali tablolarını Uluslararası Muhasebe Standartları (UMS)' na uygun olarak hazırlama zorunluluğu getirmesi etkili olmuştur (Aycı, 2012). Avrupa Birliği' nin bu uygulama ile Avrupalı şirketler için öngördüğü faydalar 7 Haziran 2002' de AB Bildirisinde şöyle ifade edilmiştir (Brown, 2011).

"AB genelinde şirket hesaplarının daha güvenilir ve şeffaf olmasını ve daha kolay karşılaştırılabilmesini sağlayarak menkul kıymetlerdeki sınır ötesi ticaretin önündeki engelleri ortadan kaldırmaya yardımcı olacak. Bu da piyasa verimliliğini artıracak ve şirketler için sermaye artırmanın maliyetini azaltırken, sonuçta rekabet gücünü ve büyümeyi artrracaktır.".

Avrupa Birliği ülkelerinde 2005 yılından bu yana olmakla birlikte, dünya genelinde 125' den fazla ülkede uygulanan UFRS/UMS' ler, değişen ve gelişen ihtiyaçlar doğrultusunda değişmekte ve gelişimini sürdürmeye devam etmektedir (Durmuş ve Aytulun, 2016).

Bu standartların temel alınması suretiyle ülkeler de kendi standartlarını oluşturma çalışmalarını başlatmış ve Türkiye' de de başlatılan bu çalışmalar KGK (Kamu Gözetimi Muhasebe ve Denetim Standartları Kurumu) tarafindan Türkiye Finansal Raporlama Standartları (TFRS) ve Türkiye Muhasebe Standartlarının (TMS) yayımlanmasıyla sonuçlanmıştır.

2011 yılında yayımlanan 6102 sayılı Türk Ticaret Kanunu ile gerçek ve tüzel kişilere TFRS/TMS' leri, kavramsal çerçevede yer alan muhasebe ilkelerini ve bunların ayrılmaz parçası olan yorumları aynen uygulama zorunluluğu getirilmiş (Gökçen ve diğ., 2015) ve TFRS/TMS' lerin uluslararası uyumu için gerekli olan yasal zemin oluşturulmuştur.

Bu durum muhasebe bilgilerinin standartların öngördüğü şekilde üretilmesi açısından mevcut muhasebe uygulamalarında birtakım değişiklikler yaratmıştır. Standartlar ile muhasebe alanında yaşanan bu güncel uygulamaların muhasebe eğitimi içerisinde muhasebe meslek mensubu adaylarına verilmesi ve meslek mensubu adaylarının TFRS/TMS' ye ilişkin farkındalıklarının sağlanması bir gereklilik haline gelmiştir (Patro ve Gupta 2012). IAESB (Uluslararası Muhasebe Eğitimi Standartları Kurulu) Başkanı Chris Austin' in "Muhasebe eğitimi, raporlama ve denetlenmiş finansal tabloların kalitesini arttıran en temel taşıyıcıdır (TÜRMOB, 2016)." ifadesiyle de ortaya koyduğu gibi muhasebe mesleği ile sunulan hizmetin kalitesinin sağlanmasında en önemli faktör, yaşanan gelişime ve değişime adapte olarak, mesleğin gerekliliklerini karşılayabilen bir muhasebe eğitiminin varlığıdır. Bu anlamda muhasebe eğitimi alan öğrencilerin muhasebe mesleğine yön veren en güncel ve önemli gelişme olarak TFRS/TMS' uygulamalarına ilişkin farkındalığa sahip olmaları önem 
arz etmektedir. Yapılan çalışmalar (Karaca ve diğ., 2016; Gökçen ve diğ., 2015; Dalğar ve diğ., 2011; Ülkü ve Gökgöz, 2013; Aktaş ve Ertuğrul, 2013; Kurnaz, 2012; Albu ve vd.; 2012; Patro ve Gupta, 2012) da muhasebe eğitimi içerisinde TFRS/TMS uygulamalarına yer verilmesinin önemine dikkat çekmektedirler.

\section{Araştırmanın Amacı}

Bu çalışmada, muhasebe eğitimi alan lisans öğrencilerinin TFRS/TMS farkındalıklarını belirlemeye yönelik ampirik bir araştırma yapılmıştır. Bu amaçla hazırlanan anket Kastamonu Üniversitesi İtisadi ve İdari Bilimler Fakültesi' nde İşletme ile Bankacılık ve Finans bölümlerinde öğrenim gören lisans öğrencilerine uygulanmıştır. Uygulama sonucunda toplanan veriler SPSS programı ile analiz edilmiş olup, analizlerden elde edilen bulgular araştrmanın amacı doğrultusunda yorumlanmıştır.

\section{Araştırmanın Problemleri}

Muhasebe eğitimi alan lisans öğrencilerinin TRFS/TMS' ye ilişkin farkındalıklarını tespit etme amacı ile yürütülen çalışmanın problemleri şunlardır;

- Muhasebe eğitimi alan lisans öğrencileri TFRS/TMS konusunda bilgi sahibi midirler?

- Muhasebe eğitimi alan lisans öğrencileri TFRS/TMS içeriğine ilişkin yeterli bilgiye sahip midirler?

- Muhasebe eğitimi alan lisans öğrencileri TFRS/TMS içeriğine ilişkin bilgiyi hangi kaynaklardan edinmektedirler?

- Muhasebe eğitimi alan lisans öğrencilerinin TFRS/TMS' ye ilişkin farkındalık düzeyleri öğrenim görmekte oldukları bölüme göre farklılık göstermekte midir?

- Muhasebe eğitimi alan lisans öğrencilerinin TFRS/TMS' ye ilişkin farkındalık düzeyleri TFRS/TMS bilgisine sahip olma durumlarına göre farklılık göstermekte midir?

\section{Yöntem}

\section{Araştırmanın Modeli}

Bu araştırma muhasebe eğitimi alan lisans öğrencilerinin TFRS/TMS' ye ilişkin farkındalık düzeylerini ortaya koymaya yönelik betimsel bir araştırmadır.

\section{Araştırmanın Evren ve Örneklemi}

Araştırmanın evrenini Kastamonu Üniversitesi IïBF' de İşletme ile Bankacılık ve Finans bölümlerinde öğrenim görmekte olan toplam 922 lisans öğrencisi oluşturmaktadır. Araştırmaya toplam 237 öğrenci katıımıştır. Birçok otoritenin (Kerlinger, 1978; Hair ve diğ., 1998; Kline, 2011) güvenirliğin sağlanmasında ölçekte yer alan ifadenin en az on katı kadarına ulaşılmasını yeterli görmesi sebebiyle 237 katılımcının araştırma evrenini temsil ettiği kabul edilmiştir. Çünkü araştırma ölçeği 20 adet ifadeden oluşmaktadır ve on kat alındığında örneklem için 200 katılımcının yeterli olduğunu söylemek mümkündür.

Araştrma için ilgili bölümlerin seçilmesinin temel nedeni IïBF içerisinde muhasebe derslerinin bu bölümlerde daha yoğun veriliyor olmasıdır. Bu bölümlerden Bankacılık ve Finans bölümünde müfredatta TFRS/TMS uygulamalarına ilişkin ayrı bir ders bulunuyorken İşletme bölümünde müfredatta TFRS/TMS' ye ilişkin ayrı bir ders bulunmamaktadır. Müfredat farklılığının bu bölümlerde öğrenim gören katlımcıların TFRS/TMS' ye ilişkin farkındalıklarında anlamlı bir farklılık olup olmamasının tespitini mümkün kılması da bu iki bölümün araştırma evreni olarak seçilmesinin sebepleri arasındadır.

\section{Veri Toplama Aracı}

Bu çalışmada veri toplama aracı olarak anket kullanılmıştr. Daha önce yapılmış çalışmalardan (Dalğar, Çelik ve Mortaş, 2011, Patro ve Gupta, 2012; Ülkü ve Gökgöz, 2013; Erol Fidan ve Uysal, 2017;) faydalanılarak araştrma amacına uygun olarak geliştirilen araştırma anketi üç bölümden oluşmaktadır. Birinci bölümde katılımcıların demografik özelliklerine ilişkin ifadeler yer almaktadır. İkinci bölümde katılımcıların TFRS/TMS bilgilerini tespit etmeye yönelik ifadeler bulunmaktadır. Katılımcıların birinci ve ikinci bölümde yer alan ifadelere kendilerine uygun olan seçeneği seçerek cevap vermeleri istenmiştir. Anketin üçüncü bölümünde ise katlımcıların TFRS/TMS farkındalıklarını ölçmeye yönelik ölçek ifadeleri yer almaktadır. 5' li likert uygulanan ölçek ifadelerine katlımcıların 1=Kesinlik Katılmıyorum ve 5=Kesinlikle Katlıyorum arasında değişen puanlar vermeleri istenmiştir. Evreni temsil eden katılımcılar üzerinde ön uygulaması gerçekleştirilen ölçeğin Cronbach Alfa $(\alpha)$ değeri 0,87 olarak bulunmuştur.

\section{Verilerin Analizi}

Araştırmadan elde edilen veriler bilgisayar ortamına aktarılmış ve SPSS paket programında araştırma amacına uygun analizler yapılmıştır. Verilerin analizinde ikili grupların karşılaştırmasında t testi, ikiden fazla grupların karşılaştırması 
durumunda ise ANOVA testi yapılmıştır. \% 95 güven aralığında çalışılmıştır.

\section{Bulgular ve Yorumlanması}

\section{Muhasebe Eğitimi Alan Lisans Öğrencilerinin Demografik Özelliklerine İlişkin Bulgular}

Bu başlık altında araştırmaya katılan lisans öğrencilerinin demografik özelliklerine ilişkin bulgulara yer verilmiştir.

Tablo1: Muhasebe Eğitimi Alan Lisans Öğrencilerinin Demografik Özelliklerine iliş̧kin Bulgular

\begin{tabular}{lccc}
\hline Katılımcıların Demografik Özellikleri & Gruplar & $\mathbf{f}$ & $\%$ \\
\hline \multirow{2}{*}{ Cinsiyet } & Kadın & 158 & 66,7 \\
& Erkek & 79 & 33,3 \\
\hline \multirow{3}{*}{ Yaş } & $17-19$ & 57 & 24,1 \\
& $20-24$ & 175 & 73,8 \\
& $25-29$ & 3 & 1,3 \\
\multirow{2}{*}{ Bölüm } & 30 ve üzeri & 2 & 0,8 \\
\hline \multirow{3}{*}{ Sınıf } & İşletme & 117 & 49,4 \\
& Bankacılık ve Finans & 120 & 50,6 \\
\hline \multirow{2}{*}{ Öğretim Şekli } & 1. sınıf & 75 & 31,6 \\
& 2. sınıf & 83 & 35,0 \\
& 3. sınıf & 39 & 16,4 \\
& 4. sınıf & 40 & 17,0 \\
\hline
\end{tabular}

Tablo 1 incelendiğinde araştırmaya katılan lisans öğrencilerinin \% 66,7 sinin kadın, \% 33,3' ünün erkek olduğu görülmektedir. Katılımcıların $(24,1+73,8)$ \% 97,9 gibi büyük bir çoğunluğunun yaşları 17-24 aralığında değişmektedir. Lisans öğrencilerinin \% 49,4' ü İşletme bölümünden, \% 50,6’ sı Bankacılık ve Finans bölümündendir. Katılımcıların \% 31 ,6' sı 1. sınıf, \% 35' i 2. sınıf, \% 16,4' ü 3. sınıf ve \% 17' si 4. sınıftır. Katılımcıların \% 73,8' i 1. öğretimde öğrenim görmekte iken $\% 26,2^{\prime}$ si 2. öğretimde öğrenim görmektedir.

\section{Muhasebe Eğitimi Alan Lisans Öğrencilerinin TFRS/TMS Bilgilerine îlişkin Bulgular}

Bu başlık altında araştırmaya katılan lisans öğrencilerinin TFRS/TMS bilgilerine ilişkin bulgulara yer almaktadır.

Tablo 2: Muhasebe Eğitimi Alan Lisans Öğrencilerinin TFRS/TMS Bilgilerine ilişkin Bulgular

\begin{tabular}{|c|c|c|c|}
\hline $\begin{array}{l}\text { TFRS/TMS Bilgisine ilişkin Özellik- } \\
\text { ler }\end{array}$ & Gruplar & f & $\%$ \\
\hline \multirow{3}{*}{$\begin{array}{l}\text { TFRS/TMS Konusunda Bilgi Sahibi } \\
\text { Olma Durumları }\end{array}$} & Evet & 50 & 21,1 \\
\hline & Hayır & 81 & 34,2 \\
\hline & Kısmen & 106 & 44,7 \\
\hline \multirow{3}{*}{$\begin{array}{l}\text { TFRS/TMS ̇çeriğine ̇lişkin Yeterli } \\
\text { Bilgi Sahibi Olma Durumları }\end{array}$} & Evet & 14 & 5,9 \\
\hline & Hayır & 15 & 6,3 \\
\hline & Kısmen & 127 & 81,4 \\
\hline \multirow{7}{*}{$\begin{array}{l}\text { TFRS/TMS İçeriğine İlişkin Bilgiyi } \\
\text { Edinme Yolları }\end{array}$} & TFRS/TMS ile ilgili müfredatta yer alan ayrı bir dersten & 96 & 40,5 \\
\hline & Muhasebe ile ilgili diğer derslerden & 57 & 24,1 \\
\hline & Mesleki ders kitaplarından & 70 & 29,5 \\
\hline & Mesleki süreli yayınlardan & 14 & 5,9 \\
\hline & Panel, kongre, sempozyum, vb ders dışı etkinliklerden & 21 & 8,9 \\
\hline & İnternetten & 32 & 13,5 \\
\hline & Kurslardan & 3 & 1,3 \\
\hline
\end{tabular}

Tablo 2' ye göre lisans öğrencilerinin \% 65,8 $(21,1+44,7)^{\prime}$ inin TFRS/TMS konusunda bilgi sahibi oldukları, \% 34,2' sinin ise TFRS/TMS konusunda bilgi sahibi olmadıkları ortaya çıkmıştı. TFRS/TMS konusunda bilgi sahibi olanların ise \% 5,9' unun TFRS/TMS içeriğine ilişkin yeterli bilgiye sahip olduğu, \% 6,3' ünün yeterli bilgiye sahip olmadığı, \% 81,4' ünün TFRS/TMS içeriğine ilişkin kısmen yeterli bilgiye sahip olduğu görülmektedir. Öğrencilerin \% 40,5' inin TFRS/TMS 
bilgisini müfredatta yer alan ayrı bir dersten, \% 29,5' inin mesleki ders kitaplarından, \% 24,1' inin muhasebe ile ilgili diğer derslerden, \% 13,5' inin internetten, \% 8,9' unun panel, kongre, sempozyum, vb ders dışı etkinliklerden, \% 5,9' unun mesleki süreli yayınlardan ve \% 1.3' ünün kurslardan öğrendiği tespit edilmiştir.

Muhasebe Eğitimi Alan Lisans Öğrencilerinin Öğrenim Görmekte Oldukları Bölüm İle TRFS/TMS Farkındalık Düzeylerinin Karşılaştırılmasına illişkin Bulgular

Bu başlık altında, öğrencilerin, TFRS/TMS farkındalıklarını tespit etmeye ilişkin olarak sorulan 20 soruya verdikleri cevaplar ile öğrencilerin öğrenim gördükleri bölümler arasında anlamlı bir farklılık olup olmadığı tespit edilmeye çalışılmıştır. Bunun için her ifadenin; frekans, aritmetik ortalama, standart sapma ve bu dağılımla ilgili anlamlılık değerleri (t-testi sonucu) ortaya konulmuştur.

Tablo 3: Muhasebe Eğitimi Alan Lisans Öğrencilerinin Öğrenim Görmekte Oldukları Bölüm İle TRFS/TMS Farkındalık Düzeylerinin Karşılaştırılması

\begin{tabular}{|c|c|c|c|c|c|c|}
\hline & Bölümler & $\mathbf{N}$ & A.O & s.s & $t$ & p \\
\hline \multirow{2}{*}{$\begin{array}{l}\text { TFRS/TMS Farkındalığına ilişkin } \\
\text { Iffadelerin Genel Ortalaması }\end{array}$} & Işletme & 117 & 3,47 & 0,746 & \multirow{2}{*}{2,601} & \multirow{2}{*}{0,000} \\
\hline & Bankacılık ve Finans & 120 & 3,97 & 0,624 & & \\
\hline
\end{tabular}

Tablo 3' te yar alan bulgulardan anlaşılacağı üzere araştrmaya katılan lisans öğrencilerinden İşletme ile Bankacılık ve Finans bölümleri arasında TFRS/TMS farkındalık düzeyleri bakımından Bankacılık ve Finans bölümü lehine 0, 05 düzeyinde anlamlı $(0,000<0,05)$ bir farklılık bulunmaktadır. Bu tablo Bankacılık ve Finans bölümü öğrencilerinin TFRS/TMS farkındalık düzeyleri bakımından belirgin bir farkııı̆a sahip olduklarını ortaya koymaktadır. Bulgulara göre Bankacılık ve Finans bölümünde öğrenim gören lisans öğrencilerinin TFRS/TMS farkındalık düzeylerinin 3,97 ortalama ile daha yüksek, İşletme bölümü lisans öğrencilerinin 3.47 ortalama ile daha düşük olduğu ortaya çıkmıştr. Bunun sebebinin Bankacılık ve Finans bölümü ders müfredatında TFRS/TMS ile ilgili dersler bulunuyorken İşletme bölümü ders müfredatnda TFRS/TMS ile ilgili derslerin bulunmaması olduğunu söylemek mümkündür.

Muhasebe Eğitimi Alan Lisans Öğrencilerinin TFRS/TMS Bilgisine Sahip Olma Durumları İle TRFS/TMS Farkındalık Düzeylerinin Karşılaştırılmasına İlişkin Bulgular

Bu başlık altında, öğrencilerin, TFRS/TMS farkındalıklarını tespit etmeye ilişkin olarak sorulan 20 soruya verdikleri cevaplar ile öğrencilerin TFRS/TMS bilgisine sahip olma durumları arasında anlamlı bir farklılık olup olmadığı tespit edilmeye çalışılmıştır. Bunun için ifadelerin genel ortalamasının; frekans, aritmetik ortalama, standart sapma ve bu dağılımla ilgili anlamlılık değerleri (ANOVA testi) ortaya konulmuştur.

Tablo 4: Muhasebe Eğitimi Alan Lisans Öğrencilerinin TFRS/TMS Bilgisine Sahip Olma Durumları İle TRFS/TMS Farkındalık Düzeylerinin Karşılaştırılması

\begin{tabular}{lcccccc}
\hline & $\begin{array}{c}\text { TFRS/TMS Bilgisine Sahip } \\
\text { Olma Durumları }\end{array}$ & N & A.O & s.s & F & P \\
\hline & Evet & 50 & 3,97 & 0,645 & & \\
$\begin{array}{l}\text { TFRS/TMS Farkındalığına ilişkin } \\
\text { Ifadelerin Genel Ortalaması }\end{array}$ & Hayır & 81 & 3,47 & 0,809 & 8,696 & 0,000 \\
& Kısmen & 106 & 3,80 & 0,648 &
\end{tabular}

Tablo 4' te yer alan bulgular incelendiğinde TFRS/TMS bilgisine sahip olan (Evet-Kısmen) öğrenciler ile TFRS/TMS bilgisine sahip olmayan (Hayır) öğrenciler arasında TFRS/TMS farkındalık düzeyleri bakımından TFRS/TMS bilgisine sahip olan öğrenciler lehine 0,05 düzeyinde anlamlı $(0,000<0,05)$ bir farklılık olduğu görülmektedir. Tablo 4 ' e göre TFRS/ TMS bilgisine sahip olan öğrencilerin farkındalık düzeylerinin evet 3,97 ortalama ile kısmen 3,80 ortalama ile TFRS/TMS bilgisine sahip olmayan öğrencilerin farkındalık düzeyinden $(A . O=3,47)$ daha yüksek olduğu tespit edilmiştir. Bu sonuç TFRS/TMS farkındalığı açısından bilginin önemini ortaya koymaktadır.

\section{Sonuç}

Muhasebe eğitimi alan lisans öğrencilerinin TFRS/TMS farkındalıklarını inceleyen araştırmada, katılımcıların \% 66,7 sinin kadın, \% 33,3' ünün erkek olduğu, $(24,1+73,8)$ 97,9 gibi büyük bir çoğunluğunun yaşlarının 17-24 aralı̆ında oldu- 
ğu ortaya çıkmıştrr. Lisans öğrencilerinin \% 49,4' ünün İşletme bölümünden, \% 50,6' sının Bankacılık ve Finans bölümünden, \% 31,6' sının 1. sınıf, \% 35' inin 2. sınıf, \% 16,4' ünün 3. sınıf ve \% 17' sinin 4. Sınıf, \% 73,8' inin 1. Öğretim \% 26,2' sinin 2. Öğretim olduğu ortaya çıkmıştır.

Lisans öğrencilerinin \% 65,8 $(21,1+44,7)^{\prime}$ inin TFRS/TMS konusunda bilgi sahibi oldukları, TFRS/TMS konusunda bilgi sahibi olanlardan \% 5,9' unun TFRS/TMS içeriğine ilişkin yeterli bilgiye sahip olduğu, \% 6,3' ünün yeterli bilgiye sahip olmadığı, \% 81,4' ünün TFRS/TMS içeriğine ilişkin kısmen yeterli bilgiye sahip olduğu saptanmıştır.

TFRS/TMS ile ilgili bilgiyi öğrencilerin \% 40,5' inin müfredatta yer alan ayrı bir dersten, \% 29,5' inin mesleki ders kitaplarından, \% 24,1' inin muhasebe ile ilgili diğer derslerden, \% 13,5' inin internetten, \% 8,9' unun panel, kongre, sempozyum, vb. ders dışı etkinliklerden, \% 5,9' unun mesleki süreli yayınlardan ve \% 1.3' ünün kurslardan öğrendiği tespit edilmiştir.

TFRS/TMS farkındalığının öğrenim görülen bölüme göre anlamlı bir şekilde farklılaşth̆̆ı ve Bankacılık ve Finans bölümünde öğrenim gören öğrencilerin farkındalık düzeylerinin Iş̧letme bölümünde öğrenim gören öğrencilerin farkındalık düzeyinden yüksek olduğu ortaya çıkmıştır. Bankacılık ve Finans bölümündeki öğrencilerin TFRS/TMS farkındalık düzeyinin yüksek çıkması, İşletme bölüm müfredatında TFRS/TMS ile ilgili ayrıca bir ders bulunmazken, Bankacılık ve Finans bölüm müfredatında TFRS/TMS ile ilgili ayrıca ders bulunmasıyla ilişkilendirilebilir. Kurnaz (2012) yapmış olduğu çalışmada ï̈BF' de muhasebe bölümü dışında öğrenim gören öğrencilerin muhasebe standartları hakkındaki farkındalık düzeyinin muhasebe bölümünde öğrenim gören öğrencilerin farkındalık düzeyinden düşük olduğunu bulgulayarak araştırmamızla benzer bir sonuç ortaya koymuştur. Erol Turan ve Uysal (2017) da yapmış oldukları çalışmada benzer bir sonuç bularak öğrencilerin TRFS/TMS algısının bazı ifadeler için öğrenim gördükleri bölümlere göre farklılaştığını tespit etmişlerdir. Ülkü ve Gökgöz (2013), Gökçen ve diğ. (2015) de yapmış oldukları çalışmada TFRS/TMS ile ilgili derslerin müfredatta yer almasının önemine yer vermişlerdir.

Araştırma bulgularına göre TFRS/TMS bilgisine sahip olan öğrenciler ile TFRS/TMS bilgisine sahip olmayan öğrenciler arasında TFRS/TMS farkındalık düzeyleri bakımından anlamlı bir farklılık olduğu ortaya çıkmıştır. Buna göre TFRS/TMS bilgisine sahip olan öğrencilerin farkındalık düzeylerinin TFRS/TMS bilgisine sahip olmayan öğrencilerin farkındalık düzeyinden daha yüksek olduğu ortaya çıkmışır. Bu sonuç TFRS/TMS farkındalığı açısından bilginin önemini ortaya koymaktadır.

\section{5. Öneriler}

Muhasebe eğitimi alan lisans öğrencilerinin büyük bir kısmının (\% 40,5) TFRS/TMS bilgisini müfredatta yer alan ayrı bir dersten edinmiş olmaları, muhasebe meslek mensubu adayı yetiştiren üniversitelerin lisans programlarında verilen muhasebe eğitiminde TFRS/TMS eğitimini içerecek derslere yer verilmesinin gerekliliğini ortaya koymaktadır.

Her alanda olduğu gibi muhasebe eğitimi açısından da güncel bilgiye sahip olmak son derece önemlidir. Muhasebe alanında yaşanan en güncel ve önemli gelişme olarak TFRS/TMS bilgisine sahip muhasebe meslek adaylarının yetiştirilmesi muhasebe eğitiminde kaliteyi yakalamanın bir gerekliliğidir. Bu anlamda sonuçlar birlikte değerlendirildiğinde muhasebe eğitimi alan lisans öğrencilerinin TFRS/TMS konusunda bilgi edinme girişimlerinin desteklenmesi gerektiği düşünülmektedir. Bu doğrultuda lisans programlarında muhasebe eğitimi vererek muhasebe meslek mensubu adayı yetiştiren üniversitelerde muhasebe eğitiminin TFRS/TMS eğitimini içerecek şekilde yeniden yapılandırılmasını, bölüm ders müfredatlarında TFRS/TMS' ye ilişkin derslere yer verilmesini önermekteyiz.

\section{Kaynakça}

Albu, N., Albu, C.N. ve Gîrbină, M.M. (2012, May), Educating Accounting Students in an Emerging Economy - an Analysis of the Importantance of Stereotypes in Teaching IFRS, International Journal of Academic Research, 4(3), 51-57.

Aktaş, M. A., Ertuğrul, A. N. (2013). Uluslararası Finansal Raporlama Standartlarının Muhasebe Eğitimine Yansıması: Ankara' daki İşletme Yüksek Lisans Öğrencilerinin Görüşleri, Bartın Üniversitesi iïBF Dergisi, 4(7), 45-64.

Aycı, A. (2012, 16-17 Haziran). KOBі' lerin Rekabet Gücünün Artrılmasında Uluslararası Muhasebe Standartlarına Uyum Sürecinin Değerlendirilmesi, 2. Uluslararası Türk Coğrafyasında UFRS Sempozyumu Bildiriler Kitabı, Trabzon.

Brown, P. (2011, August). International Financial Reporting Standards: what are the benefits?, Accounting and Business Research, 41(3), 269-285.

Dalğar, H., Çelik, İ ve Mortaş, M. (2011). Muhasebe Öğrenimi Gören Öğrencilerin TMS/TFRS Hakkındaki Farkındalıklarına Yönelik Bir Araştırma, Süleyman Demirel Üniversitesi İktisadi ve İdari Bilimler Fakültesi Dergisi, 16(1), 217-230.

Dick, W., Missonier-Piera, F. (2010). Financial Reporting under IFRS: ATopic Based Approach, England: JohnWiley\&Sons,Ltd. 
Durmuş, H., Aytulun, A. (2016). Muhasebe Mesleğini Illgilendiren Ulusal ve Uluslararası Kuruluşlar, Risk Tabanlı Denetim ve Denetim Standartları, TMUD Yayınları: Kitap No: 11.

Erdoğan M., Ulusoy, T., Benli, T., Çakmak, F., Dengel, D. ve Civek F. (2017). Kastamonu ili Sermaye Şirketlerinin Muhasebesini Tutan SMMM 'lerin Uluslararası Finansal Raporlama Standartlarına Uygun Raporlama Yapabilme Düzeyleri ile Sermaye Şirketlerinin Finansman Kaynaklarının Maliyetlerinin Araştıılması, Mumeyek Vakfi Yayınları, No:11 ISBN 978-605-61870-8-7.

Erol Fidan, M., Uysal, T. (2017). Türkiye Muhasebe ve Finansal Raporlama Standartları Konusunda Üniversite Öğrencilerinin Algı Düzeylerinin Ölçülmesi: Bilecik Şeyh Edebali Üniversitesi Örneği, KMÜ Sosyal ve Ekonomik Araşttrmalar Dergisi, 19(33), 24-35.

Gökçen, G., Ataman, B., Cebeci, Y. ve Cavlak, H. (2015, Temmuz). Türkiye'deki Devlet Üniversitelerinin Lisans Programlarındaki Muhasebe Standartları Eğitimi Üzerine Bir Araştırma, Marmara Üniversitesi Öneri Dergisi, 11 (44), 121-145.

Hair, J. F., Anderson, R. E., Tatham, R. L. And Black, W. C. (1998). Multivariate Data Analysis. (Fifth Edition). New Jersey: Prentice-Hall Inc..

Hassan, E. A., Rankin, M. and Lu, W. (2014). The Development of Accounting Regulation in Iraq and the IFRS Adoption Decision: An Institutional Perspective, The International Journal of Accounting, 49, 371-390.

Karabayır, M. E., Ertugay, E. (2014). Finansal Raporlama Standartlarının Dünü ve Bugünü, Ankara Üniversitesi SBF Dergis,, 65(4), 195-198.

Karaca, N., Sürmeli, D., Hocaoğlu, S. (2016). Türkiye'de Lisans Düzeyinde Verilen Muhasebe Eğitiminin Muhasebe Alanında Yaşanan Gelişmeler Işığında Değerlendirilmesi, Uluslararası Yönetim İktisat ve İşletme Dergisi, ICAFR 16 Özel SayıSı, $270-281$.

Kerlinger, F. N. (1978). Foundations of Behavioral Research. New York: McGraw Hill.

Kline, R. B. (2011). Principles and Practice of Structual Equation Modeling. (Third Edition). New York: The guilford Press,

Kurnaz, N. (2012 February). Statistical Analysis of the Factors Affecting Accounting Students' Awareness of the TAS (Turkish Accounting Standards) and TFRS (Turkish Financial Reporting Standards), British Journal of Science, 4 (1), 142-156.

Madawaki, A. (2012, February). Adoption of International Financial Reporting Standards in Developing Countries: The Case of Nigeria, International Journal of Business and Management. 7(3), 152-161.

Nag, S. K. (2015, March), International Financial Reporting Standards- An Overview, International Journal of Research in Finance and Marketing, 5(3), 39- 47.

Patro, A., Gupta, V. K. (2012), Adoption of International Financial Reporting Standards (IFRS) in Accounting Curriculum in India - An Empirical Study, Procedia Economics and Finance. 2, 227 - 236

TÜRMOB İnternational Haber (2016, Ocak). IAESB Küresel Muhasebe Eğitimi İhtiyaçlarını Araştırıyor ve Gelecek Strateji ve Önceliklere İlişkin Geri Bildirim Topluyor, 11(42)

Ulusoy, T. (2008). Systematic Risk and Firm Financial Structure: Evidence on Istanbul Stock Exchange. The Business Review, Cambridge, 11(2), 226-231.

Zeff, Stephen A, Foreword by Stephen A. Zeff, Didier Bensadon and Nicolas Praquin (Ed.). (2016). IFRS in a Global World: International and Critical Perspectives on Accounting içinde (v-xi), Switzerland: Springer International Publishing. 